\title{
LES VEDETTES DU SPORT ET DES MÉDIAS INTRODUCTION
}

\author{
Damien FÉMÉNIAS ${ }^{1}$, Gérard DERÈZE ${ }^{2}$
}

Contemporain de l'avènement du cinéma, Marcel Mauss reconnaît dans la démarche des infirmières celle des actrices américaines et repère très tôt ce que les usages sociaux doivent aux représentations qu'on en donne. Quelques décennies plus tard, Edgar Morin prolonge cette réflexion et ouvre un champ de recherche, mais depuis Les Stars, force est de constater que le sens et la place des vedettes, des héros et des idoles -que produisent nos sociétés médiatisées- suscitent des questions complexes et récurrentes.

Dans ce numéro de Recherches en communication, nous tenterons de mieux comprendre le sens et de mieux identifier la place qu'occupent aujourd'hui dans les médias, parmi les vedettes du loisir ou du divertissement, les vedettes du sport.

Les vedettes $\mathrm{du}$ sport sont des acteurs exceptionnels d'aujourd'hui. Leurs actions, leurs faits et gestes sont mis en récit et leurs exploits sont rendus hypervisibles par la résonance médiatique. Ces figures sportivo-médiatiques sont à la fois des figures du loisir, des figures de l'excellence et de la performance,

1 Damien Féménias est professeur des universités à l'Université de Rouen.

2 Gérard Dérèze est professeur de communication à l'Université catholique de Louvain.

Recherches en communication, ${ }^{\circ} 50$ - Article publié le 07/10/2019 
les acteurs et les produits d'une industrie culturelle (le spectacle du sport).

Les vedettes du sport sont des figures - historiquement majoritairement masculines - dont la production, la consécration, la médiation et la réception méritent d'être questionnées. En effet l'exposition médiatique de ces vedettes nous rappelle sans cesse que le sport constitue une réalité symbolique dans laquelle se condensent et s'incarnent des aspirations et des travers de notre époque.

Quelles sont ces aspirations? Quels sont ces travers? Comment passe-t-on de champion à vedette ? Que projetons-nous sur ces figures et qu'attendons-nous d'elles ? Ces champions sont-ils des héros, des stars, des « grands singuliers »? Quels sont, au juste, la nature, la force et le sens des projections et des identifications que ces personnages suscitent ? Quelle place occupent-ils, au-delà du cercle des amateurs de sport, dans le panthéon imaginaire de nos sociétés contemporaines? Quelle est la longévité et quels sont les espaces de leur exposition?

Les vedettes sportives, ces « héros en survêtement», sont des figures sociales et médiatiques plus complexes, plus paradoxales et plus ambivalentes qu'on ne le pense à première vue. Si l'économie symbolique de l'héroïsme sportif semble reposer sur des mécanismes récurrents, la " consécration sportive » a historiquement connu des formes différentes, et le « champion par procuration » de l'époque aristocratique a cédé la place aux figures modernes du « gentleman amateur » et du « professionnel » avant d'atteindre, avec le développement des médias, l'âge de la « célébrité ». L'histoire médiatique du sport permet d'identifier des périodes, des acteurs et des formes matérielles de consécration : les vedettes n'existent pas en dehors des dispositifs d'écriture et de narration des spectacles sportifs, ni en dehors des processus et des contingences médiatiques qui les produisent. Il s'agit, dès lors, d'identifier des groupes sociaux (journalistes, écrivains, metteurs en scène, fans/supporters, agents de joueurs, sponsors/ publicitaires...) et des mondes par l'activité desquels le vedettariat sportif advient et évolue. 
Les dynamiques sociales et médiatiques de la reconnaissance ne sont, pour autant, ni étanches, ni exclusifs, ni figés. Du people (Laure Manaudou, David Beckham, Tiger Woods...) aux affaires (Serge Blanco, Bernard Laporte, Dejan Veljkovic...), de la politique (Maurice Herzog, Michel Platini...) aux mondes de l'art (Jean-Pierre Rives, Eric Cantona, Yannick Noah...), on voit qu'il y a lieu de repérer et de distinguer les périmètres (culturels, sociaux et géographiques) au sein desquels les notoriétés sportivomédiatiques s'établissent.

Les vedettes du sport sont aussi (souvent) des étoiles filantes et cette dimension éphémère donne à penser le temps des médias. Leur carrière sportive, relativement courte à l'échelle d'une carrière professionnelle, ne les expose au public le plus souvent que temporairement. On peut, de ce fait, interroger le processus médiatico-sportif ininterrompu de production continue de « grands sportifs » et de " grandes sportives » et aussi la manière dont leur " dégradation / disparition » est reçue par les publics (grand public, amateurs, supporters). De façon contrastée, certaines vedettes s'inscrivent dans la durée : Pourquoi ? Comment ? Par quels processus?

Ces quelques constats paradoxaux n'épuisent évidemment pas le sujet.

Le sport médiatisé est une production culturelle nourrie de significations multiples et variées et un miroir dans lequel se projettent, se réfléchissent et parfois s'écrasent les « contradictions objectives » et les "difficultés subjectives » de notre condition anthropologique.

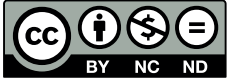 \\ Publié sous la licence Creative Commons}

«Attribution - Pas d'Utilisation Commerciale - Pas de Modification 4.0 International» (CC BY-NC-ND 